\title{
A multiparametric evaluation of quantum dot size and surface-grafted peptide density on cellular uptake and cytotoxicity
}

\author{
Christy Maksoudian ${ }^{\dagger}$, Stefaan J. Soenen $^{\dagger}$, Kimihiro Susumu $^{\ddagger}, \S$, Eunkeu Oh${ }^{\S}$, Igor L. Medintz", \\ and Bella B. Manshian*, ${ }^{\dagger}$ \\ ${ }^{\dagger}$ NanoHealth and Optical Imaging Group, Department of Imaging and Pathology, KU Leuven, Herestraat \\ 49, B3000 Leuven, Belgium \\ ${ }^{\ddagger}$ KeyW Corporation, Hanover, MD 21076, USA \\ ${ }^{\S}$ Optical Sciences Division Code 5600, \\ "Center for Bio/Molecular Science and Engineering Code 6900 \\ U.S. Naval Research Laboratory \\ Washington, DC 20375, USA
}

Corresponding author:

Email: bella.manshian@kuleuven.be

Tel: +3216323058 


\begin{abstract}
Despite the progress in nanotechnology for biomedical applications, great efforts are still employed in optimizing nanoparticle (NP) design parameters to improve functionality and minimize bio-nanotoxicity. In this study, we developed CdSe/CdS/ZnS core/shell/shell quantum dots (QDs) that are compact ligandcoated and surface-functionalized with an HIV-1-derived TAT cell-penetrating peptide (CPP) analog to improve both biocompatibility and cellular uptake. Multiparametric studies were performed in different mammalian and murine cell lines to compare the effects of varying QD size and number of surface CPPs on cellular uptake, viability, generation of reactive oxygen species, mitochondrial health, cell area, and autophagy. Our results showed that the number of cell-associated NPs and their respective toxicity is higher for the larger QDs. Meanwhile, increasing the number of surface CPPs also enhanced cellular uptake and induced cytotoxicity through the generation of mitoROS and autophagy. Thus, here we report the optimal size and surface CPP combinations for improved QD cellular uptake.
\end{abstract}

\title{
Introduction
}

Nanoparticles (NPs) hold approximately $85 \%$ of the share value of nanomaterials worldwide. ${ }^{1}$ In the field of biomedical research, interest in quantum dot (QD) NPs, in particular, is still significantly rising due to their supremely advantageous optical properties. ${ }^{2}$ QDs are semiconductor nanocrystals comprised of a core with a diameter ranging typically ranging between 1 and $10 \mathrm{~nm}$ and possess high brightness, photostability, ${ }^{3}$ broad excitation and narrow and size-tunable emission spectra ${ }^{4}$ which render them powerful probes for in vitro and in vivo biomedical imaging applications at the molecular and diagnostic level. ${ }^{5-7}$ The ability of multiple-sized QDs to be excited by a single wavelength allows efficient multiplexing and the simultaneous detection of various biomarkers in tissue sections, improving the predictability of clinical outcomes. ${ }^{8,9}$ Secondly, their high intensity and resistance towards photobleaching permit the longterm tracking of live, single-molecules, which offers detailed information on intracellular trafficking and processing. ${ }^{10,11}$ QDs are also being extensively used in the development of anticancer interventions either directly for photodynamic ${ }^{12-15}$ or photothermal ${ }^{16-18}$ therapy applications, or in combination with existing drug formulations, ${ }^{5,19,20}$ rendering them as promising theranostic agents.

Among the family of QDs, cadmium-based NPs are the most 'classical' and frequently used as their synthesis protocols have become well-established over the years. ${ }^{21}$ However, due to the high potential toxicity of free cadmium ions to biological systems - as publicized in several in vitro studies ${ }^{22,23}$ - as well as the generation of reactive oxygen species (ROS) upon direct illumination that may induce DNA damage 
and apoptosis, ${ }^{24-26}$ these QDs remain limited in their translation towards biomedical applications and are currently restricted to proof-of-concept studies, although the slow release of toxic cadmium ions can be exploited for cancer therapy, ${ }^{18,27,28}$ and great effort is being invested here to retain the optico-physical properties of cadmium-containing particles. ${ }^{29,} 30$ One method aimed at improving biocompatibility is the alteration of the QD composition to a cadmium-free material. ${ }^{29}$ Other methods to reduce toxicity include coating the QDs with polyethylene glycol (PEG) ${ }^{31,32}$ or other double polymer-silica and ligands that are able to increase QD resilience against degradation and prevent agglomeration, ${ }^{33,34}$ as well as adding a passivating shell layer that shields the cadmium-containing core from the environment. ${ }^{35,36}$ Besides $^{3}$ composition, nanomaterial size has also been shown to be a key determinant of its toxicity. ${ }^{37-39}$ In general, scaling down materials to the nanoscale increases their surface area to volume ratio and the degree of material interaction with their surroundings, rendering them potentially more toxic. As such, in designing QD formulations, it is imperative to optimize parameters such as composition, coating, and size to fit their desired biocompatibility profile. ${ }^{40,41}$

One major area of interest in developing NPs for certain biomedical applications such as probes, contrast agents, and drug delivery systems, is in improving their uptake into the cytoplasm or their endosomal escape. ${ }^{42}$ While most NPs are easily uptaken by endocytosis, variations in $\mathrm{pH}$ and the presence of hydrolytic enzymes within endosomes lead to the degradation of the NPs or their coating, ${ }^{43,44}$ altering their physicochemical properties and resulting in reduced fluorescence intensity in the case of some QDs as well as increased cellular toxicity. ${ }^{45}$ Existing physical and chemical methods aimed at improving NP cytosolic access include electroporation ${ }^{46,47}$ and the use of transfection agents. ${ }^{48,}{ }^{49}$ Another more practical and biocompatible option is the functionalization of the NP surface with cell-penetrating peptides (CPPs), which have been shown to be capable of crossing the cell membrane barrier and of delivering cargoes that are otherwise impenetrable on their own. ${ }^{50,51}$ The change in particle surface chemistry associated with CPP coverage can be exploited to fine-tune particle-cell interactions, thus, affecting the particle toxicity profile and colloidal stability. It has previously been shown that the mechanism of CPP internalization is concentration-dependent, where relatively low peptide concentrations lead to endocytosis and higher amounts are suggested to cause direct uptake, although the latter process remains somewhat controversial. ${ }^{52}$, 53 Some of the most commonly used CPPs include varieties of the transactivator-of-transcription (TAT)-peptide derived from the HIV-1 regulatory protein, which have already been shown to mediate the cellular uptake of various materials through the association of localized consecutive repeats of positively-charged amino acids with negatively-charged heparan sulfate 
proteoglycans (HSPGs) or similar molecules on cellular membranes. ${ }^{54-56}$ To this day, great efforts are being invested in optimizing CPP-mediated material delivery by modifying CPP sequences and motifs. ${ }^{57-59}$

In the current study, we developed water soluble CdSe/CdS/ZnS core/shell/shell QDs that are surfacefunctionalized with modified TAT-peptide derivatives consisting of consecutive repeats of cationic arginine residues at the $\mathrm{N}$-terminal and anionic histidine residues at the $\mathrm{C}$-terminal. The incorporation of polyhistidine into the sequence allowed the peptide to easily bind to the zinc on the QD surface. ${ }^{8}$ The QDs were coated with modified compact ligands (CL4), which have already been shown to exhibit greater cellspecific uptake compared to unmodified PEG. ${ }^{60}$ While various studies have looked into the effect of NP size or the density of CPPs on potential cytotoxicity, the exact link between these particular characteristics along with NP uptake levels on toxicological effects remains elusive. This is partly driven by the complexity and multifactorial aspects related to the field of bio-nanointeractions. Therefore, in order to obtain a comprehensive understanding of the effects of QD size, concentration, and surface CPP coating density on cellular functionality and thereby derive the optimal design parameters for biocompatibility, we conducted an exhaustive multiparametric study of varying these variables on QD uptake and cytotoxicity using high-content imaging in different mammalian and murine cell lines. NP exposure levels and cellassociated QDs were expressed in different units, being the total number of QDs, their total volume (i.e. mass) or total surface area, in order to determine which of these parameters is most indicative of the toxicity of "bare" (CL4 only) and CPP-coated QDs. The ensuing analyses delineate a positive relationship between cytotoxicity and number of cell-associated QDs, QD size and surface CPPs, resulting from increased membrane damage, mitochondrial ROS (mitoROS) generation and autophagy induction.

\section{Results and discussion}

\section{QDs synthesis and ligand coating}

Three CdSe/CdS/ZnS core/shell/shell QD samples with varying sizes were utilized in the present study. These included 520-, 620-, and 662- nm emitting QDs with average diameters of 4.0, 9.7, and $13.4 \mathrm{~nm}$ as determined by high resolution transmission electron microscopy (TEM), see Figure 1a,b. These are referred to as the $Q D_{S}, Q D_{M}$, and $Q D_{L}$ samples for small, medium, and large, respectively. The native hydrophobic growth ligands were cap-exchanged with the CL4 solubilizing ligand to provide the QDs with their final colloidal-stability. This ligand has a demonstrated record of robustness, long-lifetime, and application in a variety of very challenging biological environments. ${ }^{8,36,58,60,61}$ 
a) $\mathrm{QD}_{\mathrm{S}} \lambda_{\mathrm{Em} .}=520 \mathrm{~nm}$ Diam. $4.0 \pm 0.4 \mathrm{~nm} \mathrm{QD}{ }_{\mathrm{M}} \lambda_{\mathrm{Em} .}=620 \mathrm{~nm}$ Diam. $9.7 \pm 1.0 \mathrm{~nm} \mathrm{QD}_{\mathrm{L}} \lambda_{\mathrm{Em} .}=662 \mathrm{~nm}$ Diam.13.4 $1.3 \mathrm{~nm}$
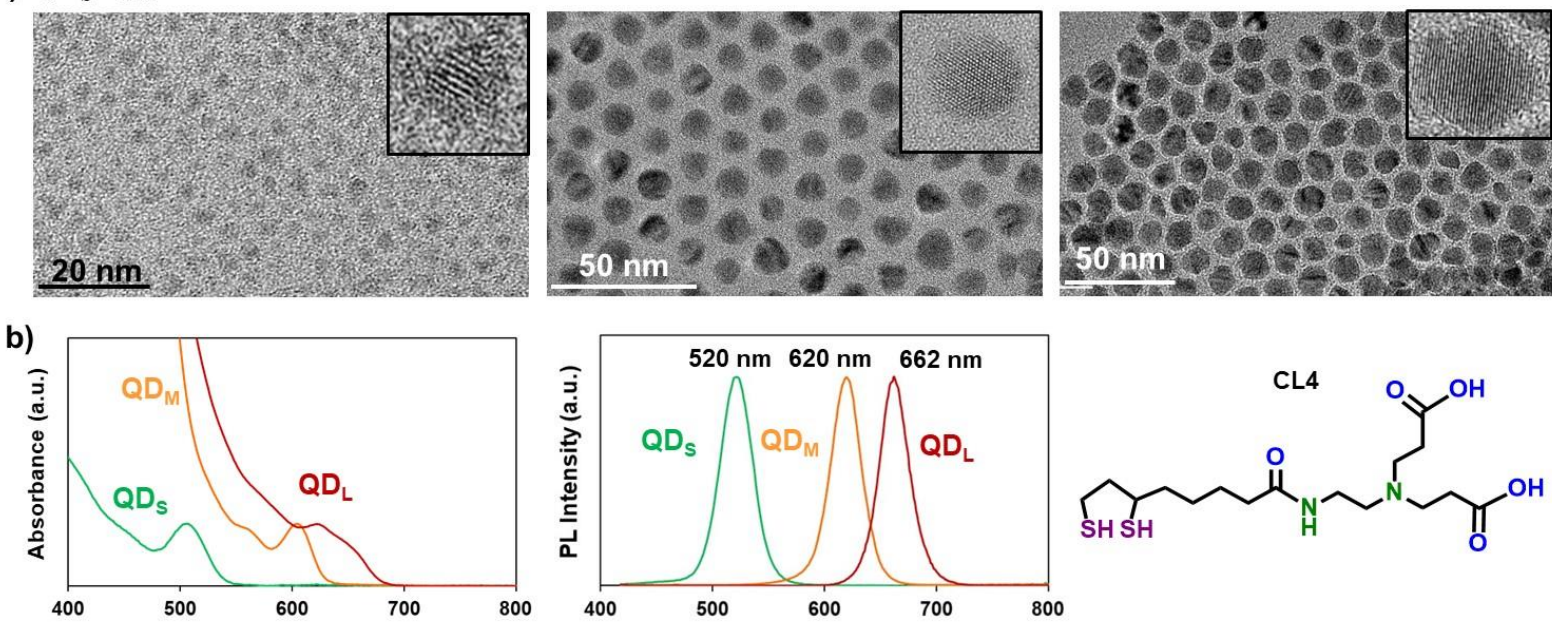

c)
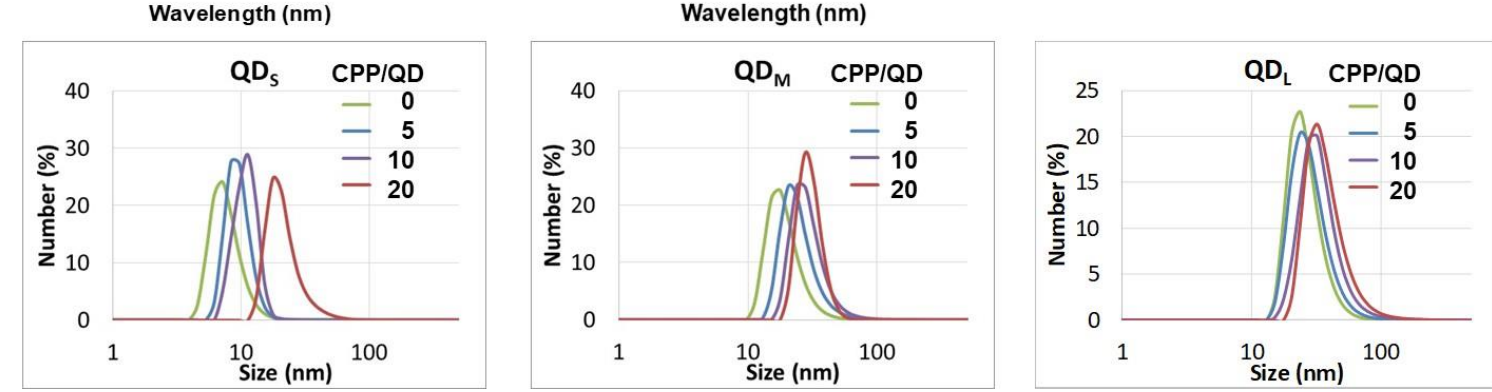

Figure 1: a) Representative TEM micrographs of each of the QD samples utilized in this study. High resolution close-ups are shown inset. The QD emission maxima $\left(\lambda_{E M}\right)$ is presented along with the mean diameter (Diam.). b) Normalized absorption (left) and photoluminescence (PL, middle) of the QD samples along with the chemical structure of the CL4 solubilizing ligand (right) shown in the reduced state. C) Results from measuring each of the QD hydrodynamic diameter $\left(H_{D}\right)$ as prepared and then as assembled with the average increasing ratio of CPP as indicated. Individual values are given the SI.

QD properties pertinent to this study are also detailed in Table 1. These materials were chosen specifically to allow, amongst other things, an evaluation of what affects, if any, alterations in QD diameter alone would exert on subsequent cellular uptake and viability with all other properties kept consistent.

Table. 1. QD physicochemical properties.

\begin{tabular}{|c|c|c|c|c|c|c|c|c|c|}
\hline Sample & $\begin{array}{c}\lambda_{\text {EM }} \text { Max. } \\
(\mathrm{nm})\end{array}$ & $\begin{array}{c}\text { Av. } \\
\text { diameter } \\
(\mathrm{nm})\end{array}$ & $H_{D}(\mathrm{~nm})$ & $\mathrm{SA}\left(\mathrm{nm}^{2}\right)$ & Vol. $\left(\mathrm{nm}^{3}\right)$ & $\begin{array}{l}\text { SA/Vol. } \\
\text { ratio }\end{array}$ & $\begin{array}{c}\text { \# of } \\
\text { surface } \\
\mathrm{ZnS}^{1} \\
\end{array}$ & $\begin{array}{l}\text { Predicted } C d \\
\text { atoms per } Q D^{2}\end{array}$ & $\begin{array}{l}\text { Measured Cd } \\
\text { atoms per QD }\end{array}$ \\
\hline QDs & 520 & $4.0 \pm 0.4$ & $7.7 \pm 2.2$ & 50 & 34 & 1.47 & 337 & 123 & 108 \\
\hline $\mathrm{QDM}_{\mathrm{M}}$ & 620 & $9.7 \pm 1.0$ & $19.5 \pm 7.1$ & 295 & 478 & 0.62 & 2180 & 4678 & 5291 \\
\hline$Q D_{L}$ & 662 & $13.4 \pm 1.3$ & $26.6 \pm 8.8$ & 564 & 1260 & 0.45 & 4235 & 13637 & 19056 \\
\hline
\end{tabular}

Notes: All QDs have CdSe/CdS/ZnS core/shell/shell structures.

$H_{D}$ - hydrodynamic diameter with CL4 ligand. SA - surface area. Vol. - volume. 
${ }^{1}$ Estimated number of ZnS displayed on the QD surface. ${ }^{2}$ Estimated number of $\mathrm{Cd}$ atoms per QD. Zeta potentials for the respective QDs are shown in the Supporting Information (SI).

\section{CPP functionalization}

To conjugate the peptides to the QDs, we utilized hexahistidine (His) 6 driven metal-affinity coordination to the zinc $(\mathrm{Zn})$ on the QD surface. This high-affinity interaction $\left(K_{\mathrm{d}} \sim 1 \mathrm{nM}\right)$ occurs almost spontaneously and ratiometric attachment of the peptide to the QDs was achieved by controlling the molar ratio of each material during self-assembly. ${ }^{62}$ The current CPP sequence, a functional analog of the canonical HIV TAT sequence, has a long history of effectively delivering QDs and other nanoparticulate materials to various cell and tissue types. ${ }^{8,36,58,60,61}$ This CPP, $\mathrm{NH}_{2}$-(Arg) ${ }_{9}$-GLAA-Aib-SGWK-(His) 6 - $\mathrm{CONH}_{2}$, was designed to be modular in nature where the $(\mathrm{His})_{6}$ provides the $\mathrm{QD}$ attachment sequence, $\mathrm{W}$ is utilized for its strong absorbance to quantitate the peptide, SG functions as a flexible point to allow the peptide to bend away from the QD surface and extend between the surface ligands, GLAA-Aib is a linker to add length to the peptide, and $(\mathrm{Arg})_{9}$ provides the key charge-based interactions with the cell that defines its use. ${ }^{50,54-61} \mathrm{CPP}$ conjugation to the QDs was confirmed with dynamic light scattering. As shown in Figure 1c, addition of each increasing ratio of CPP to the QDs resulted in a discrete increase in the hydrodynamic diameter $\left(H_{\mathrm{D}}\right)$ of the QDs confirming assembly. For the smallest QDs, this increase was more pronounced than for the largest QDs.

\section{In vitro cellular interaction with QDs}

QD delivery to cells was to be evaluated with as prepared CL4-QDs and those that displayed CPP to actively facilitate uptake at defined ratios. As models for our in vitro studies and in order to cover a range of cell types that represent the various routes of exposure to the QDs and investigate the potential specificity of QD effects towards different tissues, the human umbilical vein cells (EA.hy926), foreskin fibroblasts (HFF1), and bronchial epithelial cells (Beas-2B), as well as murine mesenchymal stem cells (mMSC) were used.

\section{Cellular uptake and toxicity of as prepared CL4-QDs}

In order to gain a comprehensive understanding of the effects of the different QDs, upon interaction with the investigated cells, we examined the toxicity of the NPs on the tested cells and explored possible mechanisms involved in the observed toxic effects. As such, we first evaluated uptake efficiencies of the varying QDs of different sizes and concentrations. Results were compared and uptake was expressed in terms of the number $\left({ }^{*} 100\right)$, surface area $\left({ }^{*} 100,000 \mathrm{~nm}^{2}\right)$ and volume $\left({ }^{*} 100,000 \mathrm{~nm}^{3}\right)$ of cell-associated 
NPs (Figure 2a) to allow for a comprehensive understanding of the effects of varying QD properties on these parameters. While the number of QDs taken up by the cells was derived using inductively coupled plasma mass spectrometry (ICP-MS), the surface areas and volumes of the differently sized cell-associated QDs were estimated based on the assumption that the particles are perfectly spherical. In order to further clarify the association between varying QD size and the observed uptake levels we presented the cellular exposure concentrations in terms of molarity, surface area and volume. Here, surface area and volume were expressed as fold increases (ratios) between the different sized QDs, starting off from a theoretical surface area of 1 for $\mathrm{QD}_{\mathrm{s}}$ at $5 \mathrm{nM}$. Doubling the concentration to $10 \mathrm{nM}$ would then entail doubling the surface area of $Q D_{s}$ to 2, and so on. As expected, cellular $Q D$ uptake is a concentration-dependent mechanism, where increasing exposure concentration results in a higher uptake. Also, in alignment with existing literature describing NP uptake via endocytosis as a saturable mechanism, ${ }^{63-65}$ the uptake efficiency of the QDs - calculated as the ratio of cell-associated particles to the total number of particles administered - decreased with higher concentrations. Additionally, the levels of uptake were found similar but not identical for all cell lines. This small variability could be associated with differences in cell surface properties affecting cell-bioconjugate interactions. ${ }^{66}$ Other factors that may cause differences in cellular QD uptake levels include 1) the overall size of the cell (the larger the cells, the more the available surface area for QD interaction with the cell membrane and thus the higher internalization), as well as 2) differences in the metabolic activity and general pino- and endocytosis levels of the different cells. ${ }^{67,68}$ Due to these strong similarities in the results from the various cell lines and, hence, the overlapping conclusions, only the results obtained from the EA.hy926 cell lines are displayed and discussed below. Results from the remaining cell types are included in the Supporting Information (SI) section.

Interestingly, we discovered a positive correlation between QD size and cellular uptake levels with increasing molarity, where approximately $600 \mathrm{nM}$ of $\mathrm{QD}_{s}$ was required to achieve uptake above the ICPMS detection threshold levels while this was only $300 \mathrm{nM}$ for $\mathrm{QD}_{M}$ and $100 \mathrm{nM}$ for $\mathrm{QD}_{L}$. This is mainly due to the detection limit of ICP-MS in analyzing metal ions in rather dilute biological samples. While the number of cell-associated QDs may increase even at the lowest concentrations used, this will only become detectable when sufficient $\mathrm{Cd}^{2+}$ ions are cell-associated. Given the difference in QD size, which correlates with the difference in the levels of $\mathrm{Cd}^{2+}$ ions, this results in more $\mathrm{Cd}^{2+}$ for the bigger QDs than for the smaller ones, suggesting that even if uptake levels would have been identical, $Q D_{L}$ would be detected sooner than $Q D_{M}$ and $Q_{s}$. This increase in uptake of the larger QDs was not associated with cellular toxicity at any of the tested concentrations (Figure 2b), which could suggest that the CL4 coating and outermost ZnS shell render CdSe/CdS/ZnS QDs of this size biocompatible. ${ }^{61}$ However, upon comparing uptake levels of the 
differently sized QDs as a function of surface area and volume, the results vary considerably. When the same number of NPs are used (at the same fold increase in surface area or volume), the total number of cell-associated QDs correlates with increasing diameters. This is in line with previous findings, where the total level of NP-cell interactions was found to be maximal around 40-50 nm, and active endocytosis transport mechanisms would favor higher levels of NP-cell membrane interactions. ${ }^{39}$ When QDs are presented to the cells at the same total surface area or the same mass (volume) i.e. the same level of $\mathrm{Cd}^{2+}$, there is a strong inverse correlation with QD size. This is logically derived from the fact that the total number of discrete $\mathrm{QD}_{s}$ required to reach the same total surface area or total volume will be far higher than for the larger QDs.

a)
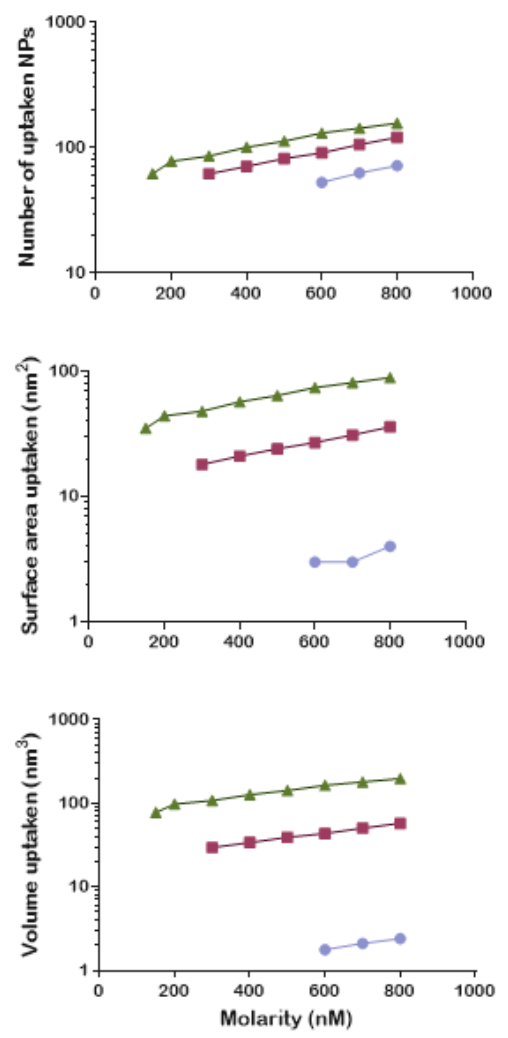

b)

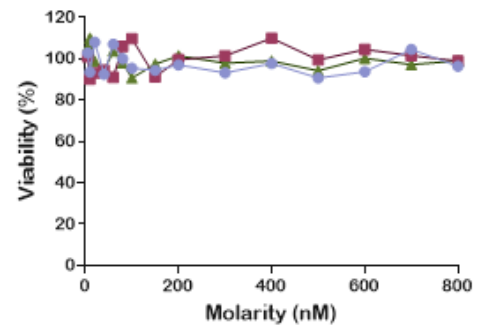

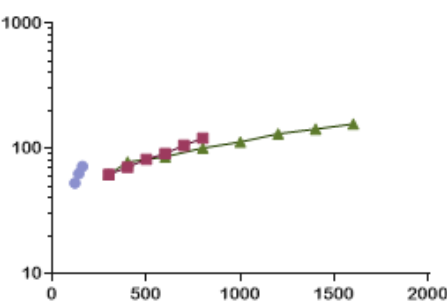
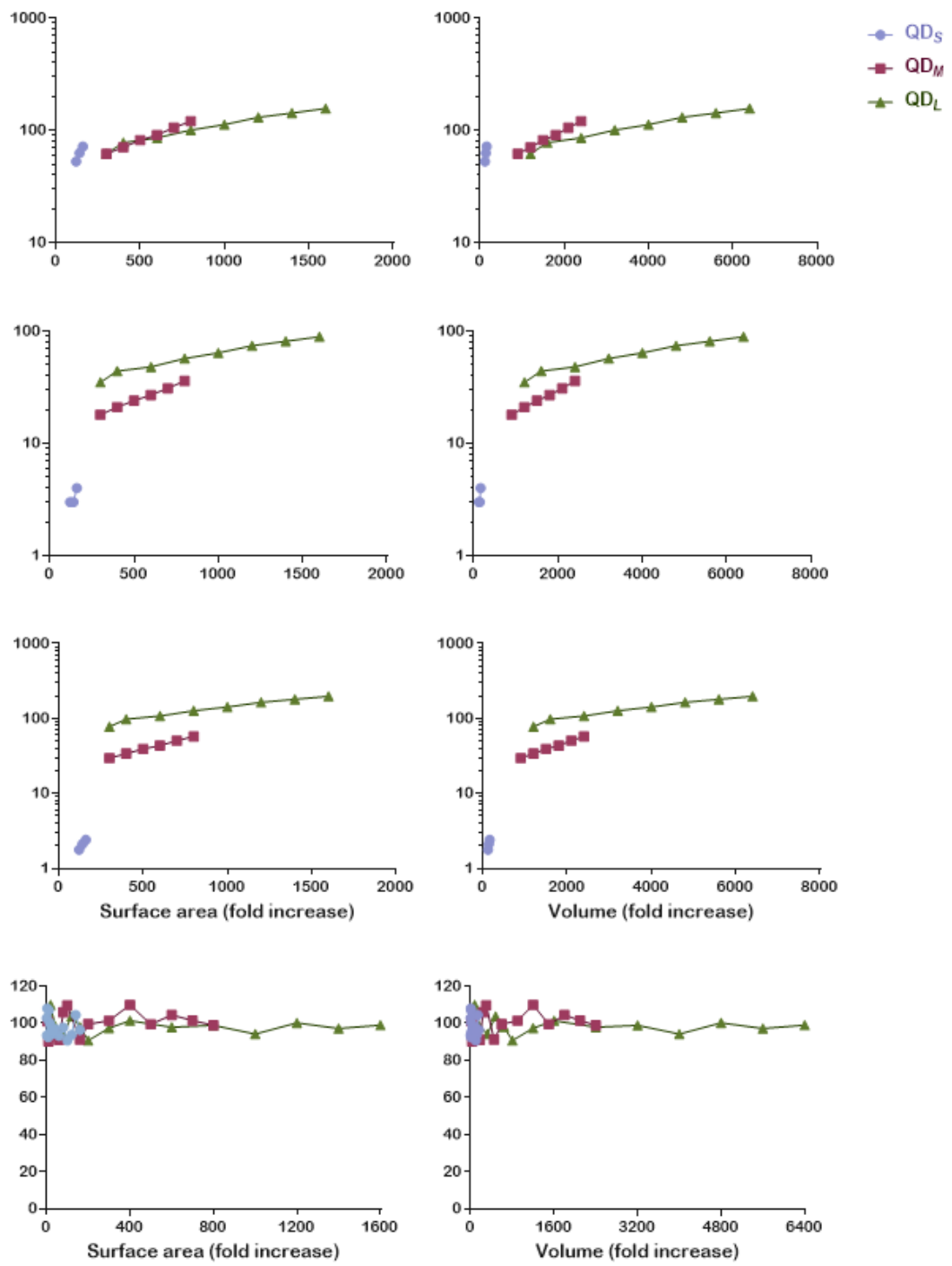

Figure 2: a) Cellular uptake of the differently sized QDs with no CPP present for EA.hy926 cells expressed on a logarithmic scale in terms of ICP-MS-derived number of uptaken NPs $(* 100)$ as well as the calculated 
surface area and volume uptaken ( $* 100,000 \mathrm{~nm}^{2} \mathrm{or} \mathrm{nm}^{3}$, respectively). Uptake is displayed as a function of administered concentration expressed in molarity $(\mathrm{nM})$, surface area and volume (fold increases from a surface area starting point of 1 for $Q D_{s}$ at $5 \mathrm{nM}$ ). The data points for the smaller $x$ values for each QD size curve are not visible as they equal zero. b) Cellular viability (percent changes from control) due to treatment with different concentrations and sizes of QDs.

\section{Cellular uptake and toxicity of peptide-QD assemblies}

Upon functionalization of the QD surface with increasing numbers of peptides, the QD concentration required to induce uptake significantly decreased, with only $10 \mathrm{nM}$ needed to achieve uptake of QDs with 5 surface peptides and even $5 \mathrm{nM}$ for the uptake of QDs with 10 surface peptides for all particle sizes and cell types (Figure 3a). Similar to the cellular uptake of the CL-4 only coated QDs, increasing the number of peptides on the surface of the particles had a much greater effect on the cellular uptake of the larger QDs. The efficiency, due to increasing surface peptide functionalization, also decreased, further highlighting that NP uptake of these QDs occurs under a saturable mechanism. The more pronounced effect of the peptides on the larger QDs corresponds to recent data, where it has shown that the density of cell penetrating peptides plays a major role in determining their cellular interactions. ${ }^{69-71}$ Thus, the ICP-MS studies performed here show that cellular uptake of the CdSe/CdS/ZnS core/shell/shell QDs has a direct correlation with particle concentration, size, and surface peptide functionalization. These findings are in line with similar studies focusing on peptide-covered gold NPs ${ }^{57}$ and QDs ${ }^{72}$ of different sizes. Of interest to note here is that for the smaller sized QDs, the initial 'jump' in cellular QD levels was observed following the administration of around $100 \mathrm{nM}$ concentration, while any further increases in molar concentrations did not result in significant increases in uptake levels. For larger QDs, the initial 'jump' is similar but stronger, but this is also followed by a clearer increase in cellular QD levels at higher concentrations. The cellular toxicities associated with increasing surface CPP were then analyzed as shown in Figure $3 \mathrm{~b}$. In line with the data from cellular uptake, increasing surface peptide concentration induces higher cellular toxicity, with the strongest correlation between uptake and viability being $R^{2}=-0.81$ and $R^{2}=-0.64$ for increasing concentrations of $\mathrm{QD}_{L}$ and $\mathrm{QD}_{S}$, respectively, with 20 surface CPPs. This trend in toxicity can also be attributed to the increasing surface positive charge of the particles associated with increasing number of surface-functionalized CPPs, as shown by the zeta potential values in Table S1 of the SI section. This trend is in line with previously published data that indicate higher cellular toxicity associated with positively charged quantum dots ${ }^{73,74}$ as well as iron oxide ${ }^{75}$ and gold nanoparticles ${ }^{76}$, as compared with their negatively charged counterparts that display low to no toxicity. 
In Table 2, we estimate the amount or number of QDs added per cell during incubation, and the subsequent cell-associated QD amount (i.e. QD taken up by that cell or associated with the QD surface during ICP-MS analysis) and the comparable Cd ion amount after delivery at the highest QD concentration $(800 \mathrm{nM})$. Data from the EA.hy926 cells are presented as a representative cell line because of the similar trends seen in the other cell types. For the largest $Q D s\left(Q_{L}\right)$ without peptide, 1.6E10 QDs/cell were incubated and 1.6E4 QDs/cell were associated after delivery, and the comparable Cd amount were 3.0E8 atoms/cell. With the highest peptide conjugation ratio (20 peptides/QD), $\mathrm{QD}_{L}$ were delivered or associated with a much higher efficiency ( 20 times more), 3.0E5 QD/cell, and the amount of cell-associated Cd/cell reached 5.7E9/cell. This large amount of QD and Cd per cell caused $\sim 43 \%$ of cell mortality. The $Q D_{M}$ showed $27 \%$ cell death with $1.1 \mathrm{E} 9$ of $\mathrm{Cd} /$ cell after being incubated with the same QD-CPP concentration (800 nM $\mathrm{QD}, 1.6 \mathrm{E} 10 \mathrm{QDs} / \mathrm{cell})$ but less internalized QDs (2.1E5 QD/cell). The $\mathrm{QD}_{s}$ showed almost no toxicity ( 8\%) at the same QD concentration. We attribute this to the smaller amount of QD and Cd present in the cells. 

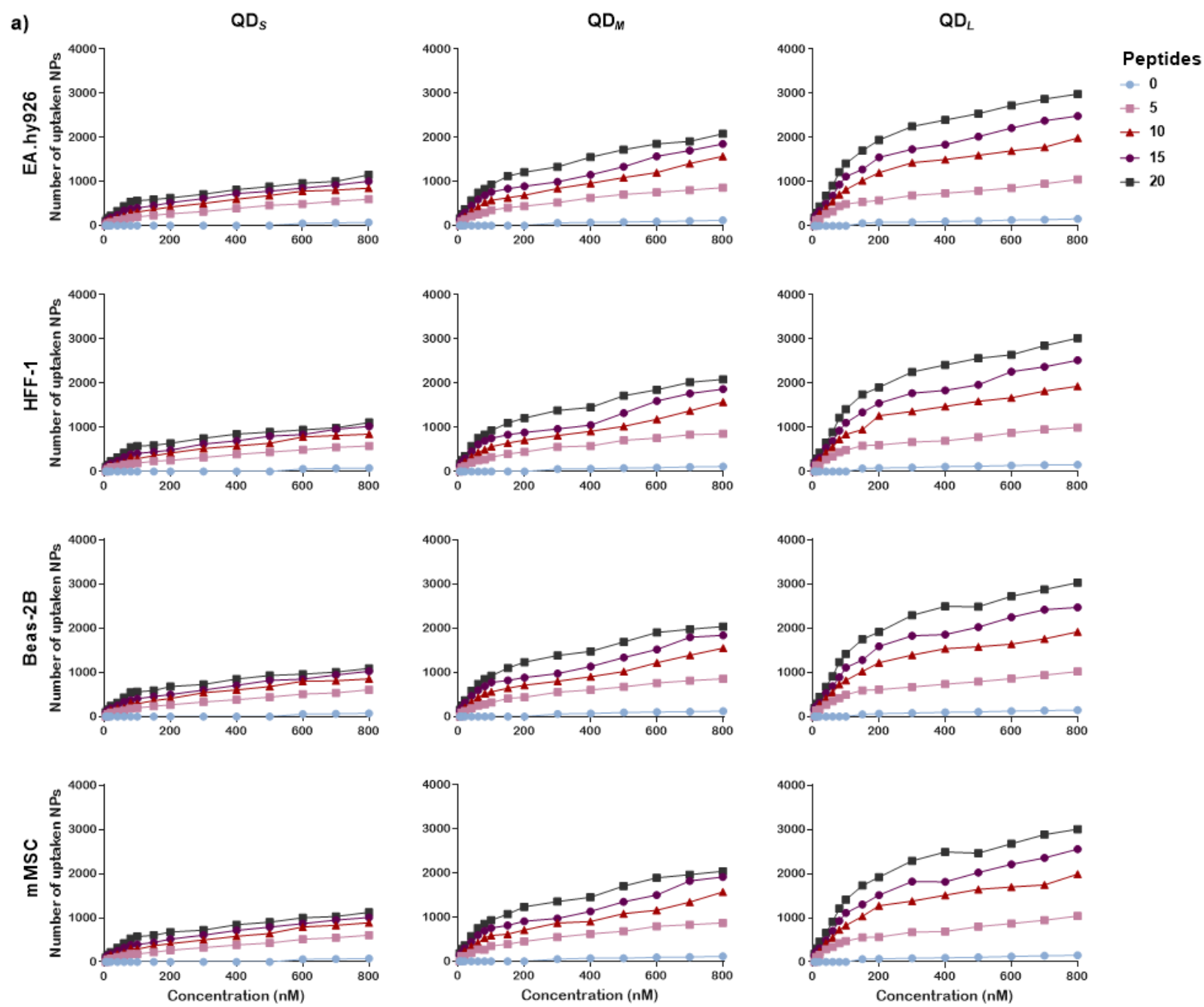

b)
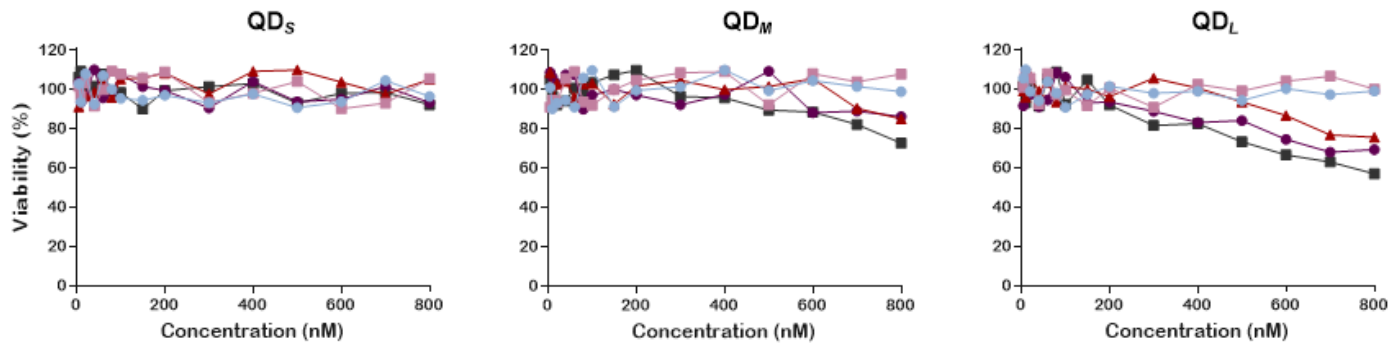

Figure 3: a) Number of cell-associated particles $(* 100)$ due to increases in molar concentrations of QDs that are surface functionalized with 0, 5, 10, 15 and 20 CPPs for the EA.hy926, HFF-1, Beas-2B and mMSC cell lines. b) Viability of EA.hy 926 cells (\% changes from control) due to treatment with different concentrations, sizes, and peptide functionalization of QDs. 
Table. 2. Estimated efficiency of QD uptake and delivery to the EA.hy926 cell line.

\begin{tabular}{|ccccccc|}
\hline & $\begin{array}{c}\text { Sample } \\
(\mathbf{8 0 0} \mathbf{n M})\end{array}$ & $\begin{array}{c}\text { Incubated QD } \\
\text { /cell }\end{array}$ & $\begin{array}{c}\text { Uptaken QD } \\
\text { /cell }\end{array}$ & $\begin{array}{c}\text { Incubated Cd } \\
\text { /cell }\end{array}$ & $\begin{array}{c}\text { Uptaken Cd } \\
\text { /cell }\end{array}$ & $\begin{array}{c}\text { Cell viability } \\
\text { (\%) }\end{array}$ \\
\hline \multirow{2}{*}{ No Peptide } & $\mathrm{QD}_{S}$ & $1.6 \mathrm{E} 10$ & $7.2 \mathrm{E} 3$ & $1.7 \mathrm{E} 12$ & $7.8 \mathrm{E} 5$ & 96.4 \\
\cline { 2 - 7 } & $\mathrm{QD}_{M}$ & $1.6 \mathrm{E} 10$ & $1.2 \mathrm{E} 4$ & $8.5 \mathrm{E} 13$ & $6.4 \mathrm{E} 7$ & 98.9 \\
\cline { 2 - 7 } & $\mathrm{QD}_{L}$ & $1.6 \mathrm{E} 10$ & $1.6 \mathrm{E} 4$ & $3.1 \mathrm{E} 14$ & $3.0 \mathrm{E} 8$ & 99 \\
\hline \multirow{2}{*}{$\begin{array}{c}\mathbf{2 0} \\
\text { Peptides/QD }\end{array}$} & $\mathrm{QD}_{S}$ & $1.6 \mathrm{E} 10$ & $1.2 \mathrm{E} 5$ & $1.7 \mathrm{E} 12$ & $1.2 \mathrm{E} 7$ & 92.3 \\
\cline { 2 - 7 } & $\mathrm{QD}_{M}$ & $1.6 \mathrm{E} 10$ & $2.1 \mathrm{E} 5$ & $8.5 \mathrm{E} 13$ & $1.1 \mathrm{E} 9$ & 72.7 \\
\cline { 2 - 7 } & $\mathrm{QD}_{L}$ & $1.6 \mathrm{E} 10$ & $3.0 \mathrm{E} 5$ & $3.1 \mathrm{E} 14$ & $5.7 \mathrm{E} 9$ & 56.9 \\
\hline
\end{tabular}

Cd refers to the number of $C d$ atoms

\section{In vitro toxicity screening and mechanistic studies}

High-content imaging was used to understand the effects of varying QD concentration, size and surface functionalization on multiple cellular parameters, including; cell viability, membrane damage, mitochondrial health, mitoROS, cell area and autophagy. These results also showed that the effects of QDcell interactions across all cell lines were similar, and thus we present and discuss only data obtained for the EA.hy926 cell line. First, we analyzed the effects of increasing NP molar concentration and size of the CL-4 only QDs on the various cellular parameters mentioned above. As shown in the top heat map in Figure $4 a$, there is no distinct trend in the data. These results highlight that cellular exposure to increasing sizes and concentrations of the CL-4 only $\mathrm{CdSe} / \mathrm{CdS} / \mathrm{ZnS}$ QDs has no particular effect on cellular functionality and integrity, further affirming the biocompatibility of these CL4-coated particles. These data are seemingly contradictory to earlier results, where, for example, a size-dependent activation of autophagy was observed when cells were exposed to QDs. ${ }^{72}$ However, the surface coating of the QDs used and the level of cell-associated QDs is of primordial importance in observing any cytotoxicity. Our results, therefore, exemplify the excellent colloidal stability and shielding effect of the CL4 coated particles. Upon cellular treatment with 20 CPP-coated QDs (bottom heat map in Figure 4a), the effects of increasing QD size become more apparent, particularly for higher molar concentrations. In Figure $4 \mathrm{~b}$, we display the effects of varying all the NP factors; size and CPP content on each cellular health parameter. The degree of impact of each variable appears to be identical for every measured output. In general, while there is a clear gradient impact starting at approximately $200 \mathrm{nM}$ for the largest QDs with increasing number of surface-CPPs, this trend is only apparent starting at $500 \mathrm{nM}$ for the medium sized QDs, and even more, only at the highest molar concentration of $800 \mathrm{nM}$ for the smallest QDs. 
As expected, an increase in cytotoxicity was correlated with higher membrane damage as a result of successful particle internalization. The Live-Dead Green dead cell stain (Molecular Probes, Life Technologies Europe, BV, Belgium) was used as a marker for membrane damage. Then, mitochondrial health was calculated as a function of mitochondrial stress, where a less elongated more spherical morphology is associated with damaged mitochondria, while mitoROS generation was measured as a marker for oxidative stress based on the increasing levels of fluorescence intensities between the control and QD-treated samples. In line with the previous data for all cell lines, the higher cellular toxicity and membrane damage associated with increasing QD concentration, size, and CPP functionalization resulted in higher mitoROS generation and thus compromised mitochondrial health. These data suggest that the induced cytotoxicity may be partly due to the oxidative stress generated by the QDs. Finally, we investigated the effects of the various QDs on the levels of cellular autophagy, a process in which autophagosomes recruit activated LC3 proteins onto their membranes, engulf damaged organelles, and recycle vital cellular components. Once again, higher cellular uptake due to increasing QD concentration, size and CPP functionalization resulted in higher levels of autophagy.

Overall, these data support the occurrence of both mechanisms that were described earlier. As the toxicity of the QDs correlates with the level of cell-associated QDs, this can lead to membrane damage when high levels of QDs with positively charged CPPs bind to the cell surface and result in tight interactions and deformations of the negatively charged plasma membrane; which at high levels can lead to cell death. ${ }^{77}$, ${ }^{78}$ The generation of mitoROS and mitochondrial damage on the other hand are less likely to result from the direct perturbations in the plasma membrane caused by cell-surface attached QDs. mitoROS is most likely generated in the endosomes, where the NPs will locate, as is common for many types of NPs including QDs. ${ }^{79-81}$ Mitochondrial damage is often a secondary effect caused by the elevated mitoROS levels, and is not necessarily a direct effect of the NPs themselves. ${ }^{82-84}$ The upregulation of autophagy is also likely linked to the occurrence of mitochondrial damage, where autophagy at high levels can indeed result in cell death, ${ }^{85,86}$ but autophagy is primordially a cellular defense mechanism, aimed at helping the cell to recover from induced damage by segregating damaged organelles and recycling them for the generation of novel cellular organelles. ${ }^{87}$ The latter has also, recently, been described for QDs, where autophagy had been shown to be a secondary cellular defense mechanism, ${ }^{88}$ as also indicated by our own data, where autophagy only occurs at high levels of mitoROS and mitochondrial damage. 

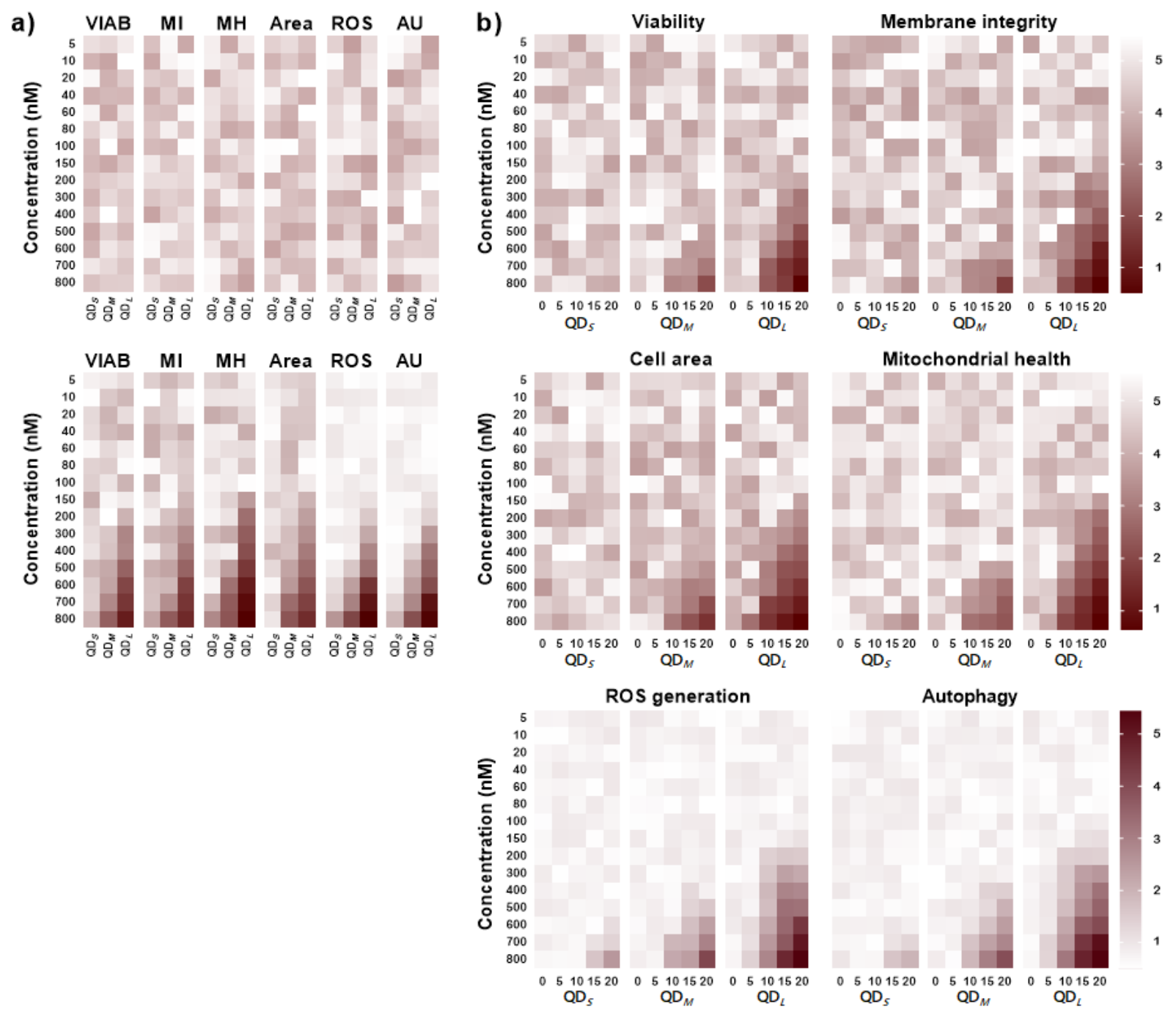

Figure 4: Heat maps displaying percent changes in viability (VIAB), membrane integrity (MI), mitoROS generation (mitoROS), mitochondrial health (MH), cell area (Area), and autophagy (AU) due to increasing QD size from left to right for the different molar concentrations of particles for the EA.hy926 cell line. Scales for the respective parameters are shown on the right $(60 \%$ to $100 \%$ for $\mathrm{VIAB}, \mathrm{MI}, \mathrm{MH}, \mathrm{Area}, 100 \%$ to $270 \%$ for ROS and $A U$ ). a) Top and bottom heat maps represent the data for QDs with no surface CPPs and 20 CPPs, respectively. b) Percent changes in cellular parameters due to increases in surface CPPs (from left to right) for each QD size and molar concentration. The numbered scales represent the fold changes in percentage.

\section{Conclusions}

In this study we demonstrated the complexity of bio-nano-interactions and the multifactorial aspects to be considered in understanding and interpreting them. We showed that correlating NP uptake to cellular toxicity levels reveal varying results depending on the parameter considered for the NP measurement; that is, whether one looks at molarity, surface area or volume. Cell type variation revealed no notable difference in the uptake levels and in the toxicity profile of the QDs. We further demonstrated that the 
functionalization of the different sized QDs with 20 CPPs improved their cellular uptake levels at the same time rendered them more toxic. In conclusion, we report in this study that CPP functionalization can improve cytosolic uptake of QDs and enhance their signal. More importantly, given that the varying reports on NP toxicity has been one of the major limitations for their translation into the clinic, a careful understanding of the complex relationship between QD physicochemical properties, CPP functionalization, and QD dosage parameters can directly help tune and modulate the toxicity of the QDs to fit their desired biocompatibility profile.

\section{Materials and Methods}

Detailed descriptions of QD synthesis and all the experimental formats, chemicals, instruments and analysis can be found in the Materials and Methods and accompanying SI.

\section{Cell-penetrating peptides}

The H6-TAT analog CPP sequence used was $\mathrm{NH}_{2}-(\mathrm{Arg})_{9}$-GLAA-Aib-SGWK-(His) ${ }_{6}-\mathrm{CONH}_{2}$ (MW 3101), where Aib is aminoisobutyric acid and $\mathrm{CONH}_{2}$ represents an amide group blocking the C-terminal carboxyl group. This peptide was obtained commercially from Bio-Synthesis (Lewisville, Texas USA). The peptides underwent preliminary desalting as described. ${ }^{62}$ They were then quantified, lyophilized, and stored at $20^{\circ} \mathrm{C}$ until needed. Prior to use, the peptides were re-dissolved in a small volume of dimethyl sulfoxide (DMSO) and diluted to the desired working concentrations in PBS.

\section{Self-assembly of QD-CPP bioconjugates}

The CPPs were conjugated onto the surface of the QDs through metal affinity coordination of the (His) 6 imidazole groups on the His side chains to the Zn on the QD surface. For each QD size, 0, 5, 10, 15 or 20 peptides were added, and the bioconjugates were incubated at room temperature for 30 minutes. The ratio of peptide to QD achieved is based on the molar ratio added and follows a Poisson distribution. For instance, a peptide to QD molar ratio of 1:10 results in approximately 10 peptides being conjugated to a single QD.

\section{Cell culture}

EA.hy926, HFF-1, Beas-2B, and mMSC cell lines were all purchased from ATCC and maintained in $75 \mathrm{~cm}^{2}$ flasks in a humidified atmosphere at $37^{\circ} \mathrm{C}$ and $5 \% \mathrm{CO}_{2}$. Cells were passaged upon $80 \%$ confluency. All the cells were cultured in high glucose Dulbecco's Modified Eagle Medium (DMEM) with 2 mM L-glutamine. 
For the EA.hy926, Beas-2B and mMSC cell lines, the DMEM was supplemented with $10 \%$ fetal bovine serum, with an additional $10 \%$ horse serum for the mMSCs and $1 \%$ fungizone and penicillin/streptomycin for the EA.hy926 cells. HFF-1 cells required medium supplemented with 15\% FBS.

\section{Cell-bioconjugate interactions studies}

All cell types were seeded at $3 \times 10^{3}$ cells per well in a 96-well plate and were left to adhere to the bottom of the wells overnight in a humidified atmosphere at $37^{\circ} \mathrm{C}$ and $5 \% \mathrm{CO}_{2}$. The cells were then incubated for 6 hours in with 4.0, 9.7 or $13.4 \mathrm{~nm}$ QDs of varying concentrations $(0,5,10,20,40,60,80,100,150,200$, $300,400,500,600,700$ and $800 \mathrm{nM})$ and ratios of QD-CPP bioconjugates (0, 5, 10, 15 or 20 peptides per QD) in their respective growth media. The ICPMS and high-content imaging studies that followed were based on previously established methods, for which sample preparation and staining procedures are provided in the SI.

\section{Bioconjugate cellular uptake}

To quantify the amount of $\mathrm{Cd}^{2+}$ per cell using ICPMS, an external calibration was first applied by diluting a standard $\mathrm{Cd}^{2+}$ solution (ALFA Johnson Matthey, Karlsruhe, Germany) in the same background solution as the samples. These samples were previously prepared to contain rhodium standard to determine recovery and iridium standard as an internal standard. All samples were measured in triplicate using the following settings: rf power: 1,150 W, plasma gas flow: $15 \mathrm{~L} / \mathrm{min}$, auxiliary gas flow: $0.85 \mathrm{~L} / \mathrm{min}$, nebulizer gas flow: $1.15 \mathrm{~L} / \mathrm{min}$. For sample introduction a MicroMist nebulizer (200 $\mu \mathrm{L} / \mathrm{min})$ and a cyclonic spray chamber both from Glass Expansion (Pocasset, MA, USA) were used. The total number of QDs per cell was then calculated by treating known concentrations of $Q_{S}, Q D_{M}$ or $Q D_{L}$ with $P B S$ and aqua regia and determining the level of $\mathrm{Cd}^{2+}$ for each QD formulation. Upon determining the total $\mathrm{Cd}^{2+}$ level per cell pellet, this value was divided by the number of cells in that pellet, and by using the $\mathrm{Cd}^{2+} / \mathrm{QD}$ level the average number of QDs per cell could be determined. For the follow-up analyses, this number was also expressed in terms of surface area and volume uptaken based on the assumption that the particles are perfectly spherical. For the analysis of both cellular uptake and toxicity, the concentration administered was expressed in terms of molarity, and fold increases in surface area and volume starting from a theoretical surface area of 1 for QDs.

\section{Cell viability, membrane damage and mitochondrial health}

Treated cells were stained with Live-Dead Green dead cell and MitoTracker Red CMXRos (Molecular Probes, Life Technologies Europe, BV, Belgium), fixed with 4\% paraformaldehyde (PFA), and 
counterstained with Hoechst 33342 Nuclear Stain solution (Life Technologies, Belgium). The plates were analyzed using the InCell analyzer 2000 (GE Healthcare Life Sciences, Belgium), during which 5000 cells, per condition, were acquired in triplicates using a 20x objective lens for the DAPI/DAPI (Hoechst), FITC/FITC (Live-Dead Green) and DsRed/DsRed (MitoTracker Red CMXRos) channels. The acquired images were processed using the InCell Investigator software (GE Healthcare Life Sciences, Belgium). In calculating cell viability, cells were first segmented based on the Hoechst stain, and the perinuclear region was identified by expanding the stain threshold and considering the original nuclear stain images as seed, before calculating viability as the difference between the total number of cells and dead cells. Specifically, dead cells were determined based on their clear green nuclei and the level of membrane damage was measured according to the number of green dots localized in the perinuclear area. Finally, for mitochondrial health, the total area of cellular mitochondria was used as a marker for mitochondrial stress, where a less elongated more spherical morphology is associated with damaged mitochondria, and the level of mitoROS was calculated based on fluorescence intensity. The respective channel was segmented using the Hoechst images as seed. The degree of cell viability, membrane damage and mitochondrial health were rendered relative as a percentage of the control values.

\section{Autophagy}

Treated cells were fixed, made permeable and blocked before being stained with primary mouse anti-LC3 antibody (Cell Signaling Technologies, Belgium), secondary AF400-conjugated goat anti-mouse IgG antibody (Invitrogen, Belgium), and ultimately Hoechst. High-content imaging of the plates was performed in a similar fashion to the previous stainings using a 60x objective for the DAPI/DAPI (Hoechst) and FITC/FITC (LC3) channels instead. The level of autophagy was determined by first segmenting the cells according to the nuclear stain then according to the cell cytoplasm (FITC), taking into consideration the nuclear stain images as seed. The values of the cellular intensity were normalized against the control values to obtain relative levels of autophagy as percentages.

\section{Acknowledgements}

S.J.S. acknowledges the financial support of the European Commission under the Horizon 2020 framework for ERC (ERC StG 750973), FWO research project (GOB2919N) and KULeuven Internal Funds C2 (3M180306). I.L.M. acknowledges the Office of Naval Research, the U.S. Naval Research Laboratory (NRL), and the NRL Nanosciences Institute for funding. E.O. acknowledges the AIMLab at the University of Maryland College Park for TEM instrumental support. 


\section{Associated Content}

The Supporting Information is available free of charge on the ACS Publications website. It includes the synthesis of the different QDs, the instrumentation used for particle characterization, and the respective data produced for the HFF-1, Beas-2B, and mMSC cell lines.

\section{References}

(1) (2018) pp 191, iGATE Research, Global.

(2) Doane, T. L., and Burda, C. (2012) The unique role of nanoparticles in nanomedicine: imaging, drug delivery and therapy. Chem Soc Rev 41, 2885-911.

(3) Zhao, M. X., and Zeng, E. Z. (2015) Application of functional quantum dot nanoparticles as fluorescence probes in cell labeling and tumor diagnostic imaging. Nanoscale Res Lett 10, 1-9.

(4) Chan, W. C., Maxwell, D. J., Gao, X., Bailey, R. E., Han, M., and Nie, S. (2002) Luminescent quantum dots for multiplexed biological detection and imaging. Curr Opin Biotechnol 13, 40-6.

(5) Mansur, A. A. P., Caires, A. J., Carvalho, S. M., Capanema, N. S. V., Carvalho, I. C., and Mansur, H. S. (2019) Dual-functional supramolecular nanohybrids of quantum dot/biopolymer/chemotherapeutic drug for bioimaging and killing brain cancer cells in vitro. Colloid Surface B 184.

(6) Zhang, H., Ba, S., Yang, Z., Wang, T., Lee, J. Y., Li, T., and Shao, F. (2020) Graphene Quantum DotBased Nanocomposites for Diagnosing Cancer Biomarker APE1 in Living Cells. ACS Appl Mater Interfaces.

(7) Carvalho, I. C., Mansur, A. A. P., Carvalho, S. M., Florentino, R. M., and Mansur, H. S. (2019) Lcysteine and poly-L-arginine grafted carboxymethyl cellulose/Ag-In-S quantum dot fluorescent nanohybrids for in vitro bioimaging of brain cancer cells. Int J Biol Macromol 133, 739-753.

(8) Boeneman, K., Delehanty, J. B., Blanco-Canosa, J. B., Susumu, K., Stewart, M. H., Oh, E., Huston, A. L., Dawson, G., Ingale, S., Walters, R., et al. (2013) Selecting improved peptidyl motifs for cytosolic delivery of disparate protein and nanoparticle materials. ACS Nano 7, 3778-96.

(9) Liu, J., Lau, S. K., Varma, V. A., Moffitt, R. A., Caldwell, M., Liu, T., Young, A. N., Petros, J. A., Osunkoya, A. O., Krogstad, T., et al. (2010) Molecular Mapping of Tumor Heterogeneity on Clinical Tissue Specimens with Multiplexed Quantum Dots. Acs Nano 4, 2755-2765.

(10) Rivera-Gil, P., Yang, F., Thomas, H., Li, L., Terfort, A., and Parak, W. J. (2011) Development of an assay based on cell counting with quantum dot labels for comparing cell adhesion within cocultures. Nano Today 6, 20-27.

(11) Clarke, S., Pinaud, F., Beutel, O., You, C. J., Piehler, J., and Dahan, M. (2010) Covalent Monofunctionalization of Peptide-Coated Quantum Dots for Single-Molecule Assays. Nano Lett 10, 2147-2154.

(12) Choi, Y. J., Kim, Y. J., Lee, J. W., Lee, Y., Lim, Y. B., and Chung, H. W. (2012) Cyto-/Genotoxic Effect of CdSe/ZnS Quantum Dots in Human Lung Adenocarcinoma Cells for Potential Photodynamic UV Therapy Applications. J Nanosci Nanotechno 12, 2160-2168.

(13) Ahirwar, S., Mallick, S., and Bahadur, D. (2020) Photodynamic therapy using graphene quantum dot derivatives. J Solid State Chem 282.

(14) Cheng, K., Zhang, X. S., An, J., Li, C., Zhang, R. Y., Ye, R., Ye, B. J., Liu, B., and Zhao, Y. D. (2019) Hitherto-Unexplored Photodynamic Therapy of Ag2S and Enhanced Regulation Based on Polydopamine In Vitro and Vivo. Chem-Eur J 25, 7553-7560. 
(15) Liu, J. T., Liu, T. R., Du, P., Zhang, L., and Lei, J. P. (2019) Metal-Organic Framework (MOF) Hybrid as a Tandem Catalyst for Enhanced Therapy against Hypoxic Tumor Cells. Angew Chem Int Edit $58,7808-7812$.

(16) Cao, Y., Wu, T., Zhang, K., Meng, X., Dai, W., Wang, D., Dong, H., and Zhang, X. (2019) Engineered Exosome-Mediated Near-Infrared-II Region V2C Quantum Dot Delivery for Nucleus-Target LowTemperature Photothermal Therapy. ACS Nano 13, 1499-1510.

Liu, H., Li, C., Qian, Y., Hu, L., Fang, J., Tong, W., Nie, R., Chen, Q., and Wang, H. (2020) Magneticinduced graphene quantum dots for imaging-guided photothermal therapy in the second nearinfrared window. Biomaterials 232, 119700.

Ma, Y. L., Yan, F., Liu, L., Wei, W. J., Zhao, Z. Y., and Sun, J. H. (2019) The enhanced photo-thermal therapy of Surface improved photoactive cadmium sulfide (CdS) quantum dots entrenched graphene oxide nanoflakes in tumor treatment. J Photoch Photobio B 192, 34-39.

Probst, C. E., Zrazhevskiy, P., Bagalkot, V., and Gao, X. H. (2013) Quantum dots as a platform for nanoparticle drug delivery vehicle design. Adv Drug Deliver Rev 65, 703-718.

Liu, F., Sun, J., Yu, W., Jiang, Q., Pan, M., Xu, Z., Mo, F., and Liu, X. (2020) Quantum dot-pulsed dendritic cell vaccines plus macrophage polarization for amplified cancer immunotherapy.

Biomaterials 242, 119928.

Ludolph, B., Malik, M. A., O'Brien, P., and Revaprasadu, N. (1998) Novel single molecule precursor routes for the direct synthesis of highly monodispersed quantum dots of cadmium or zinc sulfide or selenide. Chem Commun, 1849-1850.

Zhang, L. W., Yu, W. W., Colvin, V. L., and Monteiro-Riviere, N. A. (2008) Biological interactions of quantum dot nanoparticles in skin and in human epidermal keratinocytes. Toxicol Appl Pharm 228, 200-211.

Wang, L., Nagesha, D. K., Selvarasah, S., Dokmeci, M. R., and Carrier, R. L. (2008) Toxicity of CdSe Nanoparticles in Caco-2 Cell Cultures. J Nanobiotechnology 6, 11.

Bertin, G., and Averbeck, D. (2006) Cadmium: cellular effects, modifications of biomolecules, modulation of DNA repair and genotoxic consequences (a review). Biochimie 88, 1549-1559.

Chen, N., He, Y., Su, Y. Y., Li, X. M., Huang, Q., Wang, H. F., Zhang, X. Z., Tai, R. Z., and Fan, C. H. (2012) The cytotoxicity of cadmium-based quantum dots. Biomaterials 33, 1238-1244.

Lovric, J., Cho, S. J., Winnik, F. M., and Maysinger, D. (2005) Unmodified cadmium telluride quantum dots induce reactive oxygen species formation leading to multiple organelle damage and cell death. Chem Biol 12, 1227-1234.

Soenen, S. J., Demeester, J., De Smedt, S. C., and Braeckmans, K. (2013) Turning a frown upside down: Exploiting nanoparticle toxicity for anticancer therapy. Nano Today 8, 121-125.

Nguyen, K. C., Willmore, W. G., and Tayabali, A. F. (2013) Cadmium telluride quantum dots cause oxidative stress leading to extrinsic and intrinsic apoptosis in hepatocellular carcinoma HepG2 cells. Toxicology 306, 114-23.

Soenen, S. J., Manshian, B. B., Aubert, T., Himmelreich, U., Demeester, J., De Smedt, S. C., Hens, Z., and Braeckmans, K. (2014) Cytotoxicity of Cadmium-Free Quantum Dots and Their Use in Cell Bioimaging. Chem Res Toxicol 27, 1050-1059.

Liu, L. W., Hu, R., Law, W. C., Roy, I., Zhu, J., Ye, L., Hu, S. Y., Zhang, X. H., and Yong, K. T. (2013) Optimizing the synthesis of red- and near-infrared CuInS2 and AgInS2 semiconductor nanocrystals for bioimaging. Analyst 138, 6144-6153.

Ju, L., Zhang, G. L., Zhang, C., Sun, L., Jiang, Y., Yan, C. L., Duerksen-Hughes, P. J., Zhang, X., Zhu, X. Q., Chen, F. F., et al. (2013) Quantum dot-related genotoxicity perturbation can be attenuated by PEG encapsulation. Mutat Res-Gen Tox En 753, 54-64. 
(32) Lipka, J., Semmler-Behnke, M., Sperling, R. A., Wenk, A., Takenaka, S., Schleh, C., Kissel, T., Parak, W. J., and Kreyline, W. G. (2010) Biodistribution of PEG-modified gold nanoparticles following intratracheal instillation and intravenous injection. Biomaterials 31, 6574-6581.

(33) Gerion, D., Pinaud, F., Williams, S. C., Parak, W. J., Zanchet, D., Weiss, S., and Alivisatos, A. P. (2001) Synthesis and properties of biocompatible water-soluble silica-coated CdSe/ZnS semiconductor quantum dots. J Phys Chem B 105, 8861-8871.

(34) Selvan, S. T., Tan, T. T., and Ying, J. Y. (2005) Robust, non-cytotoxic, silica-coated CdSe quantum dots with efficient photoluminescence. Adv Mater 17, 1620-+.

(35) Walling, M. A., Novak, J. A., and Shepard, J. R. E. (2009) Quantum Dots for Live Cell and In Vivo Imaging. Int J Mol Sci 10, 441-491.

(36) Susumu, K., Oh, E., Delehanty, J. B., Blanco-Canosa, J. B., Johnson, B. J., Jain, V., Hervey, W. J., Algar, W. R., Boeneman, K., Dawson, P. E., et al. (2011) Multifunctional Compact Zwitterionic Ligands for Preparing Robust Biocompatible Semiconductor Quantum Dots and Gold Nanoparticles. J Am Chem Soc 133, 9480-9496.

(37) Ryman-Rasmussen, J. P., Riviere, J. E., and Monteiro-Riviere, N. A. (2007) Surface coatings determine cytotoxicity and irritation potential of quantum dot nanoparticles in epidermal keratinocytes. J Invest Dermatol 127, 143-153.

(38) Williams, Y., Sukhanova, A., Nowostawska, M., Davies, A. M., Mitchell, S., Oleinikov, V., Gun'ko, Y., Nabiev, I., Kelleher, D., and Volkov, Y. (2009) Probing Cell-Type-Specific Intracellular Nanoscale Barriers Using Size-Tuned Quantum Dots. Small 5, 2581-2588.

(39) Jiang, W., Kim, B. Y. S., Rutka, J. T., and Chan, W. C. W. (2008) Nanoparticle-mediated cellular response is size-dependent. Nat Nanotechnol 3, 145-150.

(40) Lewinski, N., Colvin, V., and Drezek, R. (2008) Cytotoxicity of nanoparticles. Small 4, 26-49.

(41) Verma, A., and Stellacci, F. (2010) Effect of Surface Properties on Nanoparticle-Cell Interactions. Small 6, 12-21.

(42) Cupic, K. I., Rennick, J. J., Johnston, A. P. R., and Such, G. K. (2019) Controlling endosomal escape using nanoparticle composition: current progress and future perspectives. Nanomedicine-Uk 14, 215-223.

(43) Canton, I., and Battaglia, G. (2012) Endocytosis at the nanoscale. Chemical Society Reviews 41, 2718-2739.

(44) Zhang, S., Gao, H., and Bao, G. (2015) Physical Principles of Nanoparticle Cellular Endocytosis. ACS Nano 9, 8655-71.

(45) Soenen, S. J., Montenegro, J. M., Abdelmonem, A. M., Manshian, B. B., Doak, S. H., Parak, W. J., De Smedt, S. C., and Braeckmans, K. (2015) The effect of nanoparticle degradation on poly(methacrylic acid)-coated quantum dot toxicity: The importance of particle functionality assessment in toxicology (vol 10, pg 732, 2014). Acta Biomater 12, 362-362.

(46) Kim, K., and Lee, W. G. (2017) Electroporation for nanomedicine: a review. J Mater Chem B 5, 2726-2738.

(47) Lin, J. Q., Chen, R., Feng, S. Y., Li, Y. Z., Huang, Z. F., Xie, S. S., Yu, Y., Cheng, M., and Zeng, H. S. (2009) Rapid delivery of silver nanoparticles into living cells by electroporation for surfaceenhanced Raman spectroscopy. Biosens Bioelectron 25, 388-394.

(48) Chiu, Y. L., Ali, A., Chu, C. Y., Cao, H., and Rana, T. M. (2004) Visualizing a correlation between siRNA localization, cellular uptake, and RNAi in living cells. Chem Biol 11, 1165-1175.

(49) Wang, J. D., Teng, Z. G., Tian, Y., Fang, T., Ma, J., Sun, J., Zhu, F. P., Wu, J. R., Wang, X., Yang, N. N., et al. (2013) Increasing Cellular Uptake of Mesoporous Silica Nanoparticles in Human Embryonic Kidney Cell Line 293T Cells by Using Lipofectamine 2000. J Biomed Nanotechnol 9, 1882-1890. 
(50) Gupta, B., Levchenko, T. S., and Torchilin, V. P. (2005) Intracellular delivery of large molecules and small particles by cell-penetrating proteins and peptides. Adv Drug Deliver Rev 57, 637-651.

(51) Koch, A. M., Reynolds, F., Merkle, H. R., Weissleder, R., and Josephson, L. (2005) Transport of surface-modified nanoparticles through cell monolayers. Chembiochem 6, 337-345.

(52) Di Pisa, M., Chassaing, G., and Swiecicki, J. M. (2015) Translocation Mechanism(s) of CellPenetrating Peptides: Biophysical Studies Using Artificial Membrane Bilayers. Biochemistry-Us 54, 194-207.

(53) Brock, R. (2014) The Uptake of Arginine-Rich Cell-Penetrating Peptides: Putting the Puzzle Together. Bioconjugate Chem 25, 863-868.

(54) Iversen, T. G., Skotland, T., and Sandvig, K. (2011) Endocytosis and intracellular transport of nanoparticles: Present knowledge and need for future studies. Nano Today 6, 176-185.

(55) Torchilin, V. P. (2007) Tatp-mediated intracellular delivery of pharmaceutical nanocarriers. Biochem Soc T 35, 816-820.

(56) Torchilin, V. P., Levchenko, T. S., Rammohan, R., Volodina, N., Papahadjopoulos-Sternberg, B., and D'Souza, G. G. M. (2003) Cell transfection in vitro and in vivo with nontoxic TAT peptideliposome-DNA complexes. P Natl Acad Sci USA 100, 1972-1977.

(57) Oh, E., Delehanty, J. B., Sapsford, K. E., Susumu, K., Goswami, R., Blanco-Canosa, J. B., Dawson, P. E., Granek, J., Shoff, M., Zhang, Q., et al. (2011) Cellular Uptake and Fate of PEGylated Gold Nanoparticles Is Dependent on Both Cell-Penetration Peptides and Particle Size. Acs Nano 5, 6434-6448.

(58) Gemmill, K. B., Muttenthaler, M., Delehanty, J. B., Stewart, M. H., Susumu, K., Dawson, P. E., and Medintz, I. L. (2013) Evaluation of diverse peptidyl motifs for cellular delivery of semiconductor quantum dots. Anal Bioanal Chem 405, 6145-6154.

(59) Erazo-Oliveras, A., Muthukrishnan, N., Baker, R., Wang, T. Y., and Pellois, J. P. (2012) Improving the Endosomal Escape of Cell-Penetrating Peptides and Their Cargos: Strategies and Challenges. Pharmaceuticals 5, 1177-1209.

(60) Walters, R., Medintz, I. L., Delehanty, J. B., Stewart, M. H., Susumu, K., Huston, A. L., Dawson, P. E., and Dawson, G. (2015) The Role of Negative Charge in the Delivery of Quantum Dots to Neurons. Asn Neuro 7.

(61) Walters, R., Kraig, R. P., Medintz, I., Delehanty, J. B., Stewart, M. H., Susumu, K., Huston, A. L., Dawson, P. E., and Dawson, G. (2012) Nanoparticle targeting to neurons in a rat hippocampal slice culture model. Asn Neuro 4, 383-92.

(62) Diaz, S. A., Breger, J. C., and Medintz, I. L. (2016) Monitoring Enzymatic Proteolysis Using Either Enzyme- or Substrate-Bioconjugated Quantum Dots. Method Enzymol 571, 19-54.

(63) Manshian, B. B., Pfeiffer, C., Pelaz, B., Heimerl, T., Gallego, M., Moller, M., del Pino, P., Himmelreich, U., Parak, W. J., and Soenen, S. J. (2015) High-Content Imaging and Gene Expression Approaches To Unravel the Effect of Surface Functionality on Cellular Interactions of Silver Nanoparticles. Acs Nano 9, 10431-10444.

(64) Soenen, S. J., Manshian, B., Montenegro, J. M., Amin, F., Meermann, B., Thiron, T., Cornelissen, M., Vanhaecke, F., Doak, S., Parak, W. J., et al. (2012) Cytotoxic Effects of Gold Nanoparticles: A Multiparametric Study. Acs Nano 6, 5767-5783.

(65) Soenen, S. J. H., Vercauteren, D., Braeckmans, K., Noppe, W., De Smedt, S., and De Cuyper, M. (2009) Stable Long-Term Intracellular Labelling with Fluorescently Tagged Cationic Magnetoliposomes. Chembiochem 10, 257-267.

(66) Manshian, B. B., Soenen, S. J., Al-Ali, A., Brown, A., Hondow, N., Wills, J., Jenkins, G. J. S., and Doak, S. H. (2015) Cell Type-Dependent Changes in CdSe/ZnS Quantum Dot Uptake and Toxic Endpoints. Toxicol Sci 144, 246-258. 
(67) Ketkar-Atre, A., Struys, T., Soenen, S. J., Lambrichts, I., Verfaillie, C. M., De Cuyper, M., and Himmelreich, U. (2013) Variability in contrast agent uptake by different but similar stem cell types. Int J Nanomed 8, 4577-4591.

(68) Mahmoudi, M., Laurent, S., Shokrgozar, M. A., and Hosseinkhani, M. (2011) Toxicity evaluations of superparamagnetic iron oxide nanoparticles: cell "vision" versus physicochemical properties of nanoparticles. ACS Nano 5, 7263-76.

(69) Ming, Y., Xiao, Y., Tian, Y., and Zhou, S. (2019) Cell-Membrane Penetration of Tat-Conjugated Polymeric Micelles: Effect of Tat Coating Density. Macromol Biosci 19, e1800364.

(70) Gong, L., Chen, Y., He, K., and Liu, J. (2019) Surface Coverage-Regulated Cellular Interaction of Ultrasmall Luminescent Gold Nanoparticles. ACS Nano 13, 1893-1899.

(71) Manshian, B. B., Abdelmonem, A. M., Kantner, K., Pelaz, B., Klapper, M., Nardi Tironi, C., Parak, W. J., Himmelreich, U., and Soenen, S. J. (2016) Evaluation of quantum dot cytotoxicity: interpretation of nanoparticle concentrations versus intracellular nanoparticle numbers. Nanotoxicology 10, 1318-28.

(72) Walther, C., Meyer, K., Rennert, R., and Neundorf, I. (2008) Quantum Dot-Carrier Peptide Conjugates Suitable for Imaging and Delivery Applications. Bioconjugate Chem 19, 2346-2356.

(73) Guo, G. N., Liu, W., Liang, J. G., He, Z. K., Xu, H. B., and Yang, X. L. (2007) Probing the cytotoxicity of CdSe quantum dots with surface modification. Mater Lett 61, 1641-1644.

(74) Tan, S. J., Jana, N. R., Gao, S. J., Patra, P. K., and Ying, J. Y. (2010) Surface-Ligand-Dependent Cellular Interaction, Subcellular Localization, and Cytotoxicity of Polymer-Coated Quantum Dots. Chem Mater 22, 2239-2247.

(75) Di Bona, K. R., Xu, Y. L., Ramirez, P. A., DeLaine, J., Parker, C., Bao, Y. P., and Rasco, J. F. (2014) Surface charge and dosage dependent potential developmental toxicity and biodistribution of iron oxide nanoparticles in pregnant CD-1 mice. Reprod Toxicol 50, 36-42.

(76) Schaeublin, N. M., Braydich-Stolle, L. K., Schrand, A. M., Miller, J. M., Hutchison, J., Schlager, J. J., and Hussain, S. M. (2011) Surface charge of gold nanoparticles mediates mechanism of toxicity. Nanoscale 3, 410-420.

(77) Seleverstov, O., Zabirnyk, O., Zscharnack, M., Bulavina, L., Nowicki, M., Heinrich, J. M., Yezhelyev, M., Emmrich, F., O'Regan, R., and Bader, A. (2006) Quantum dots for human mesenchymal stem cells labeling. A size-dependent autophagy activation. Nano Lett 6, 2826-2832.

(78) Frohlich, E. (2012) The role of surface charge in cellular uptake and cytotoxicity of medical nanoparticles. Int J Nanomed 7, 5577-5591.

(79) Farnoud, A. M., and Nazemidashtarjandi, S. (2019) Emerging investigator series: interactions of engineered nanomaterials with the cell plasma membrane; what have we learned from membrane models? Environ Sci-Nano 6, 13-40.

(80) Chowdary, P. D., Che, D. L., Kaplan, L., Chen, O., Pu, K., Bawendi, M., and Cui, B. X. (2015) Nanoparticle-assisted optical tethering of endosomes reveals the cooperative function of dyneins in retrograde axonal transport. Sci Rep-Uk 5.

(81) Nabeshi, H., Yoshikawa, T., Matsuyama, K., Nakazato, Y., Tochigi, S., Kondoh, S., Hirai, T., Akase, T., Nagano, K., Abe, Y., et al. (2011) Amorphous nanosilica induce endocytosis-dependent ROS generation and DNA damage in human keratinocytes. Part Fibre Toxicol 8.

(82) Shi, C. R., Liu, T., Guo, Z. D., Zhuang, R. Q., Zhang, X. Z., and Chen, X. Y. (2018) Reprogramming Tumor-Associated Macrophages by Nanoparticle-Based Reactive Oxygen Species Photogeneration. Nano Lett 18, 7330-7342.

(83) Paradies, G., Petrosillo, G., Pistolese, M., and Ruggiero, F. M. (2002) Reactive oxygen species affect mitochondrial electron transport complex I activity through oxidative cardiolipin damage. Gene 286, 135-141. 
(84) Kowaltowski, A. J., and Vercesi, A. E. (1999) Mitochondrial damage induced by conditions of oxidative stress. Free Radical Bio Med 26, 463-471.

(85) Sun, L., Li, Y., Liu, X. M., Jin, M. H., Zhang, L., Du, Z. J., Guo, C. X., Huang, P. L., and Sun, Z. W. (2011) Cytotoxicity and mitochondrial damage caused by silica nanoparticles. Toxicol in Vitro 25, 1619-1629.

(86) Liu, Y., and Levine, B. (2015) Autosis and autophagic cell death: the dark side of autophagy. Cell Death Differ 22, 367-376.

(87) Dasari, S. K., Schejter, E., Bialik, S., Shkedy, A., Levin-Salomon, V., Levin-Zaidman, S., and Kimchi, A. (2017) Death by over-eating: The Gaucher disease associated gene GBA1, identified in a screen for mediators of autophagic cell death, is necessary for developmental cell death in Drosophila midgut. Cell Cycle 16, 2003-2010.

(88) Peynshaert, K., Soenen, S. J., Manshian, B. B., Doak, S. H., Braeckmans, K., De Smedt, S. C., and Remaut, K. (2017) Coating of Quantum Dots strongly defines their effect on lysosomal health and autophagy. Acta Biomater 48, 195-205. 